\title{
Codas Syndrome
}

National Cancer Institute

\section{Source}

National Cancer Institute. Codas Syndrome. NCI Thesaurus. Code C126744.

A rare syndrome caused by mutations in the LONP1 gene. It is characterized by developmental delay, cerebral, ocular, dental, auricular, and skeletal abnormalities. 